\title{
Análise de causa e influência de elementos meteorológicos em ocorrências de incêndios em florestas de produção
}

\author{
Analysis of cause and influence of meteorological elements in fire occurrences \\ in production forests
}

\section{Weslen Pintor Canzian', Nilton César Fiedler"I, José Eduardo Macedo Pezzopane ${ }^{\mathrm{III}}$, Carlos Henrique Rodrigues Oliveira ${ }^{\mathrm{IV}}$, Elaine Cristina Gomes Silva ${ }^{\mathrm{V}}$}

\section{Resumo}

A quantidade e intensidade dos incêndios florestais têm sido destaque mediante as perdas e os impactos sociais, ambientais e econômicos. Dessa forma, o objetivo desta pesquisa foi identificar o perfil dos incêndios assim como suas causas e correlacionar a influência dos elementos meteorológicos sob as ocorrências de incêndios em florestas de produção para direcionar o uso de recursos em técnicas e medidas de prevenção, além de estruturas de combate aos incêndios florestais. O estudo teve como subsídio o banco de dados da série histórica de 10 anos de registro de ocorrência de incêndios e de variáveis meteorológicas oriundas de 45 estações meteorológicas de uma empresa produtora de eucalipto para celulose, no período de 2008 a 2017. De acordo com os resultados, 91,40\% das 32.561 ocorrências ao longo dos 10 anos foram originadas por incendiários. Além disso, justificado pela causa do incêndio, a quantidade de ocorrências entre os anos analisados apresentou correlações negativas moderada e baixa respectivamente, para umidade relativa e precipitação e correlação desprezível para temperatura média. A distribuição mensal dos incêndios destacou-se por ser uniforme ao longo do ano, uma vez que, apesar de setembro e outubro apresentarem a maior incidência das ocorrências, eles diferiram apenas de abril ao nível de $5 \%$ de probabilidade pelo teste de Tukey. Dessa forma, regiões onde a origem dos incêndios florestais é majoritariamente por ação intencional e criminosa, as ações de prevenção, monitoramento, registro de informações confiáveis e combate aos incêndios florestais devem ser planejadas contemplando todos os meses do ano.

Palavras-chave: Incendiários; Causas; Influência

\begin{abstract}
The amount and intensity of forest fires has been highlighted by the social, environmental and economic losses and impacts. Thus, the objective of this research was to identify the profile of forest fires as well as their causes and correlate the influence of meteorological elements under the occurrences of fires in production forests to direct the use of resources in prevention techniques and measures as well as structures to combat forest fires. The research had as subsidy the database of the historical series of 10 years of record of occurrence of Fires (ROIs) and meteorological elements from 45 meteorological stations of a company producing eucalyptus for cellulose, period from 2008 to 2017. According to the results, $91.40 \%$ of the 32,561 occurrences over the 10 years were originated by arsonists. Moreover, justified by the cause of the fire, the number of occurrences between the years analyzed presented moderate and low negative correlations, respectively, for relative humidity and amount of precipitation and negligible correlation for the average temperature. The monthly distribution of fires stood out because it was uniform throughout the year, since, although September and October presented the highest incidence of occurrences, they differed only from April to the level of $5 \%$ probability by the Tukey test. In this way, regions where the origin of forest fires is largely due to intentional and criminal action, the actions of prevention and combating of forest fires should be planned contemplating every month of the year.
\end{abstract}

Keywords: Arsonists; Causes; Influence

Engenheiro Florestal, Dr., Pesquisador Autônomo, Rua Sergipe s/n, Três Poderes, CEP 65903-000, Imperatriz (MA), Brasil. weslenpcanzian@ hotmail.com (ORCID: 0000-0003-0847-4692)

II Engenheiro Florestal, Dr., Professor Titular do Departamento Ciências Florestais e da Madeira, Centro de Ciências Agrárias e Engenharias, Universidade Federal do Espírito Santo, Av. Governador Lindemberg, 316, Centro, CEP 29550-000, Jerônimo Monteiro (ES), Brasil. nilton.fiedler@ ufes.br (ORCID: 0000-0002-3895-661X)

III Engenheiro Florestal, Dr., Professor Titular do Departamento Ciências Florestais e da Madeira, Centro de Ciências Agrárias e Engenharias, Universidade Federal do Espírito Santo, Av. Governador Lindemberg, 316, Centro, CEP 29550-000, Jerônimo Monteiro (ES), Brasil. Jose.pezzopane@ ufes.br (ORCID: 0000-0003-0024-4016)

IV Engenheiro Florestal, Dr., Professor do Instituto Federal do Espírito Santo, Campus Ibatiba, Av. 7 de novembro 40, Centro, CEP 29395-000, Ibatiba (ES), Brasil. engcarloshenrique@gmail.com (ORCID: 0000-0001-5867-9501)

Administradora, Dra., Professora Adjunto do Departamento de Zootecnia, Centro de Ciências Agrárias e Engenharias, Universidade Federal do Espírito Santo, Alto Universitário, Guararema, CEP 29500-000, Alegre (ES), Brasil. ecristinags@gmail.com (ORCID: 0000-0003-4214-2042) 


\section{Introdução}

De acordo com os dados da Indústria Brasileira de Árvores (IBÁ), o Brasil tem por volta de 7,8 milhões de hectares de florestas de produção, sendo esse montante representado por $71,79 \%$ de eucalipto, $20,51 \%$ de pinus e o restante constituído por seringueira, acácia, teca e paricá (INDÚSTRIA BRASILEIRA DE ÁRVORES, 2017).

Dentre as espécies florestais plantadas no país e no mundo, cada uma tem suas peculiaridades. Após dois anos de idade, os plantios de eucalipto, em sua maioria, possuem árvores com copa pequena e pouco adensada. Esse fato proporciona quantidade significativa de sub-bosque, com ocorrência de plantas competidoras que se tornam, junto com a desfolha e desrama natural das espécies de eucalipto, parte de uma camada orgânica de material combustível inflamável, o que torna essas áreas suscetíveis à ocorrência de incêndios.

Um dos acontecimentos com maior potencial de danos às florestas são os incêndios florestais, pois sua ocorrência resulta em impactos sociais, ambientais e econômicos. Especificamente em florestas de produção, os danos econômicos causados pelos incêndios florestais são diretos e podem refletir no planejamento da área afetada por um período de tempo de até um ciclo produtivo.

Devido a suscetibilidade dessas áreas frente ao alto potencial de ocorrência de incêndios, estudos de prevenção e combate são essenciais como medida de mitigação dos danos, uma vez que é possível prevenir a ocorrência de incêndios, entretanto é impossível extinguir a possibilidade de sua ocorrência.

A eficiência de qualquer estudo está em fundamentações, e na área de incêndios florestais não é diferente. O registro de ocorrência de incêndios florestais (ROIs) é fundamental no direcionamento de medidas de prevenção e combate. De acordo com Torres et al. (2006), registros históricos de incêndios florestais sólidos são essenciais em planos de prevenção e combate.

Principalmente no aspecto de prevenção, o conhecimento da causa do incêndio é primordial para que se possam ser direcionadas medidas mitigadoras. De acordo com Soares e Batista (2007), as causas dos incêndios florestais podem ocorrer de maneira natural (raios), ou por ações antrópicas, por negligência ou intencionalmente, sendo este último classificado como incêndio criminoso.

Incêndios florestais ocasionados por seres humanos de forma negligente, na maioria das vezes, são oriundos de fogueiras mal apagadas, cigarros descartados sem os devidos cuidados, ou falta de atenção no uso do fogo em locais com material combustível (OLAWOYIN, 2018).

Para Rodríguez et al. (2013), Nunes et al. (2015) e Tetto et al. (2015), a eficiência do uso de recursos na prevenção e no combate de incêndios florestais é interligado com um registro sólido e confiável, pois esse tipo de registro evita que medidas de prevenção e combate sejam equivocadas, evitando gastos muitos elevados, acima do potencial de danos/prejuízos, ou gastos muitos pequenos, que seriam ineficientes em casos de ocorrências.

As condições meteorológicas são fatores que podem limitar ou interferir as ocorrências de incêndios florestais. Para ocorrências cujas causas dos incêndios são naturais ou por ações antrópicas negligentes espera-se uma correlação fortemente positiva, dessa maneira, os estudos de prevenção e combate podem ser efetuados considerando escalas temporais medianas e/ ou longas, onde períodos de estiagem, com baixos volumes de precipitação, baixa umidade e elevadas temperaturas favorecem a ocorrência de incêndios.

Heikkila, Gronqvist e Jurvelius (2010) afirmaram que a ignição e propagação do fogo são extremamente influenciadas pelos elementos meteorológicos. Complementando essa relação, Sibanda (2011) afirmou que as condições meteorológicas interferem na severidade e quantidade de incêndios, e que dessa forma, o comportamento dos incêndios florestais é único a cada ocorrência.

De maneira geral os elementos meteorológicos são influenciadores tanto na possibilidade de ocorrência de incêndios florestais como na propagação, contudo suas influências podem ser 
tanto quanto distintas em condições onde a origem do fogo é ocasionada de forma natural e por negligência, das ocorrências proporcionadas de forma proposital por meio de ações criminosas.

O uso de dados históricos dos ROIs, associados aos elementos meteorológicos, é fundamental no direcionamento de técnicas e medidas de prevenção e combate de incêndios florestais. Dessa maneira, este estudo teve como objetivo identificar o perfil dos incêndios florestais assim como suas causas e correlacionar a influência dos elementos meteorológicos sob as ocorrências de incêndios em florestas de produção.

\section{Material e métodos}

\section{Caracterização da área de estudo}

O estudo foi realizado nas áreas de uma empresa produtora de eucalipto para celulose, com as áreas distribuídas em regiões de Mata Atlântica nas localidades de Aracruz e São Mateus, no Espírito Santo, e em Posto da Mata e Teixeira de Freitas, na Bahia, totalizando aproximadamente 220 mil ha de cultivo de eucalipto para produção de celulose. As áreas dos plantios da região do estudo são caracterizadas por apresentar relevo de plano a levemente ondulado (INSTITUTO CAPIXABA DE PESQUISA, ASSISTÊNCIA TÉCNICA E EXTENSÃO RURAL, 2011a), o que possibilita o uso da mecanização em mais de $90 \%$ das áreas, em todas as operações, desde a implantação da floresta até a colheita (Figura 1).

Figura 1 - Localização da área de estudo

Figure 1 - Location of the study site

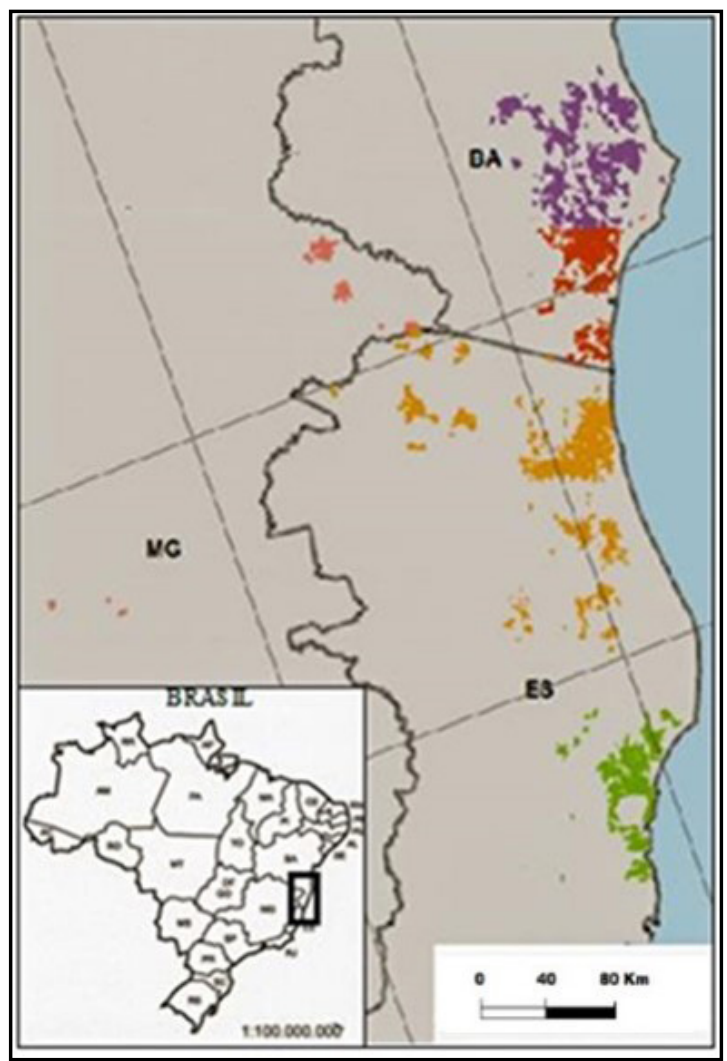

Fonte: Autores (2020) 
De acordo com o sistema de classificação climática de Köppen (1936), o clima predominante da região é do tipo Aw, quente e úmido, com estação seca no outono-inverno e estação chuvosa na primavera-verão (ALVARES et al., 2013). A temperatura média anual varia entre 26 e $29^{\circ} \mathrm{C}$ e precipitação média entre 1.200 a $1.400 \mathrm{~mm}$ (INSTITUTO CAPIXABA DE PESQUISA, ASSISTÊNCIA TÉCNICA E EXTENSÃO RURAL, 2011b).

\section{Obtenção e análise dos dados}

O estudo foi realizado com o banco de registro de ocorrência de incêndios florestais de uma empresa produtora de eucalipto para produção de celulose. O banco de dados contém registros históricos de 2008 a 2017, correspondente a um período de 10 anos, sendo composto pelas seguintes informações: número de ocorrências, causas, coordenadas geográficas, data da ocorrência e área total queimada de cada foco.

As causas dos incêndios são registradas, na maioria das vezes, pelos brigadistas e sistema de vídeo monitoramento por câmeras (Figura 2).

\section{Figura 2 - Central de vídeo monitoramento}

Figure 2 - Monitoring site by cameras

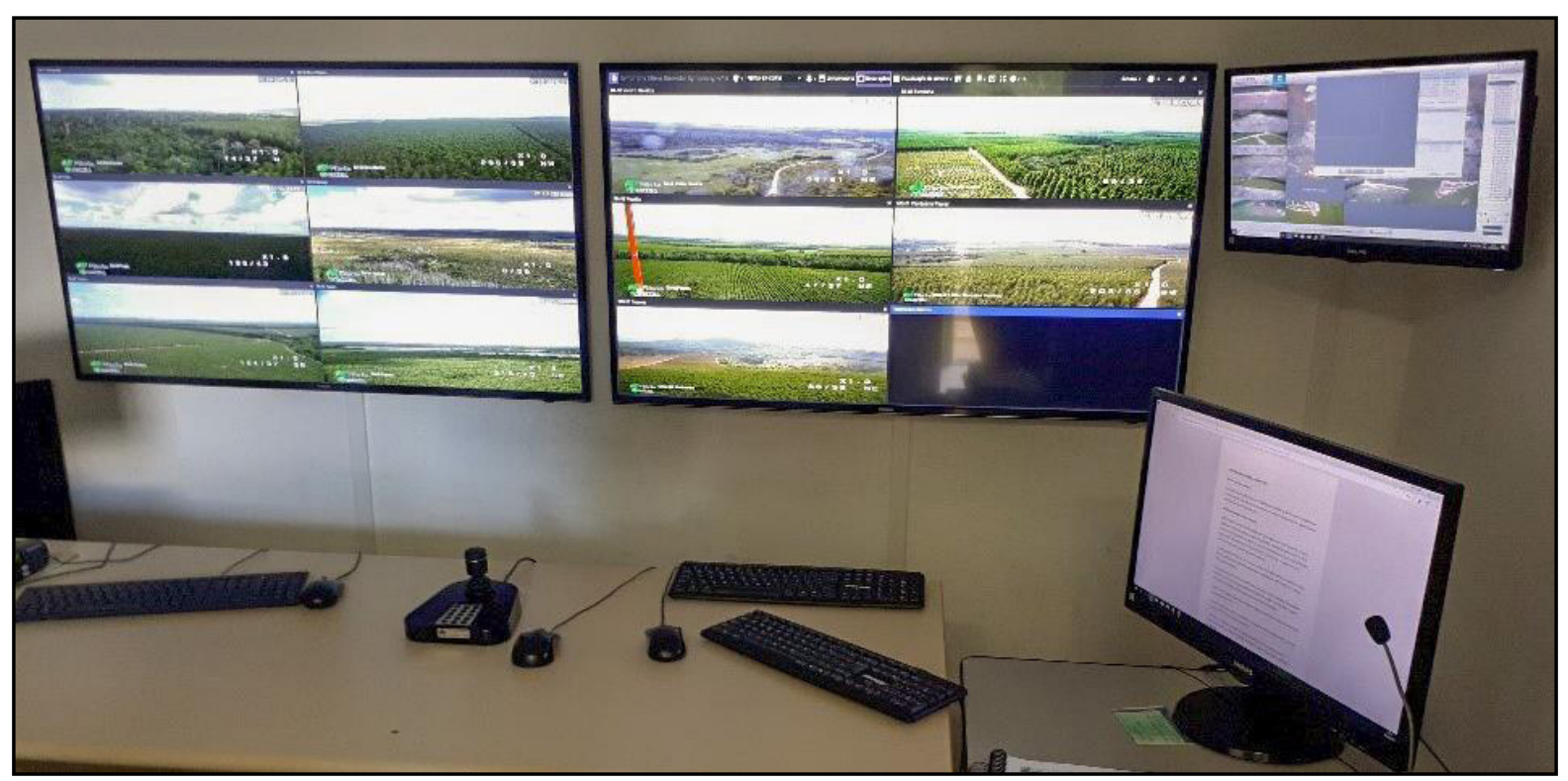

Fonte: Autores (2020)

A categorização das causas foi realizada por meio da classificação utilizada pela Food and Agricultural Organization (FAO) (SOARES, 1988), subdivididos entre oito grupos: raios, incêndio criminoso, queimas para limpeza, fumantes, operações florestais, fogos de recreação, estradas de ferro e diversos.

Os dados meteorológicos foram oriundos da estação meteorológica mais próxima da área de ocorrência dos incêndios dentre as 45 estações que estão distribuídas nas áreas da empresa. As análises de correlação foram realizadas com os elementos meteorológicos que influenciam na probabilidade de ocorrência de incêndio, sendo eles: temperatura do ar, umidade relativa do ar e precipitação.

A análise de correlação foi realizada através da estatística descritiva do coeficiente de correlação de Pearson e interpretado de acordo com a Tabela 1. 


\section{Tabela 1 - Classes de tamanho do coeficiente de correlação de Pearson e sua interpretação}

Table 1 - Size classes of Pearson's correlation coefficient and their interpretations

\begin{tabular}{cc}
\hline Classe de tamanho & Interpretação \\
\hline $\mathbf{0 , 9}$ a $1,0(-0,9$ a $-1,0)$ & Correlação positiva muito alta (negativa) \\
$\mathbf{0 , 7 0}$ a $0,89(-0,7$ a $-\mathbf{0 , 8 9})$ & Alta correlação positiva (negativa) \\
$\mathbf{0 , 5 0}$ a $0,69(-0,50$ a $-0,69)$ & Correlação positiva moderada (negativa) \\
$\mathbf{0 , 3 0}$ a $0,49(-0,30$ a $-0,49)$ & Baixa correlação positiva (negativa) \\
0 a $0,29(0$ a $-0,29)$ & Correlação desprezível \\
\hline
\end{tabular}

Fonte: Adaptado de Hinkle, Wiersma e Jurs (2003)

A distribuição mensal média, da quantidade de ocorrências de incêndios florestais da série histórica analisada, foi submetida à análise de variância. Quando o valor de " $F$ " foi significativo, as médias dos tratamentos foram submetidas ao teste de Tukey, ao nível de $5 \%$ de significância, para descobrir se existe diferença entre os meses do ano em relação à quantidade de ocorrências de incêndios florestais.

\section{Resultados e discussão}

$\mathrm{Na}$ série histórica correspondente aos 10 anos analisados, de 2008 a 2017, foram registradas 32.561 ocorrências de incêndios. Dentre as principais causas, os incêndios criminosos prevaleceram com $91,40 \%$, seguido por queimadas para limpeza $(7,84 \%)$, diversos $(0,53 \%)$, fumantes $(0,16 \%)$ e operações florestais $(0,07 \%)$. Incêndios ocasionados por fogos de recreação, raios e estradas de ferro não houve registro.

Incêndios criminosos apresentam como dificuldade o estabelecimento de estratégias de prevenção e combate, pois além de ser muito aleatório, o incêndio por essa causa dificilmente apresenta algum fator correlacionável mensurável. Ou seja, diferentemente de causas naturais onde os elementos meteorológicos norteiam as probabilidades de ocorrência de incêndios, situações onde o fogo inicia-se de maneira criminosa, basta o material combustível não apresentar altos teores de umidade para sua origem e propagação.

Ganteaume e Jappiot (2013) destacaram que incêndios causados de maneira intencional na maioria das vezes acarretam grandes incêndios por não estarem correlacionados com as condições naturais do ambiente.

Os valores encontrados na pesquisa de Tetto et al. (2015) corroboram com as encontradas no presente estudo, uma vez que seguiu a mesma lógica de causas, sendo mais expressivo os incêndios criminosos, com $54,2 \%$, seguido por $16,2 \%$ de origens de incêndios por queimas para limpeza de área.

As causas de ocorrências de incêndios são decorrentes, muito das vezes, pela característica e localidade das regiões. De acordo com Barlow et al. (2012), os incêndios de regiões tropicais em sua maioria são ocasionados por incêndios oriundos de atividades agrícolas, por meio da prática de limpeza de áreas. No estudo de Torres et al. (2016), em áreas de unidades de conservação do Brasil, as causas diversas foram as de maior significância, seguido por áreas de limpeza e incêndios criminosos.

Além das causas que originam os incêndios, o registro de ocorrência de incêndios florestais deve conter as áreas queimadas para justificar e subsidiar os valores a serem gastos com estratégias de prevenção e combate (IRLAND, 2013).

A média anual de ocorrências de incêndios florestais desse estudo foi $3.256 \mathrm{em}$ 
aproximadamente 220 mil ha de área (Figura 3), o que corresponde a 8,92 ocorrências de incêndios por dia e uma área média queimada de 2,39 ha por ocorrência.

\section{Figura 3 - Quantidade de ocorrências de incêndios $\mathrm{x}$ área média queimada durante o período de 2008 a 2017}

Figure 3 - Number of occurrences of fires x burned average area during the period from 2008 to 2017

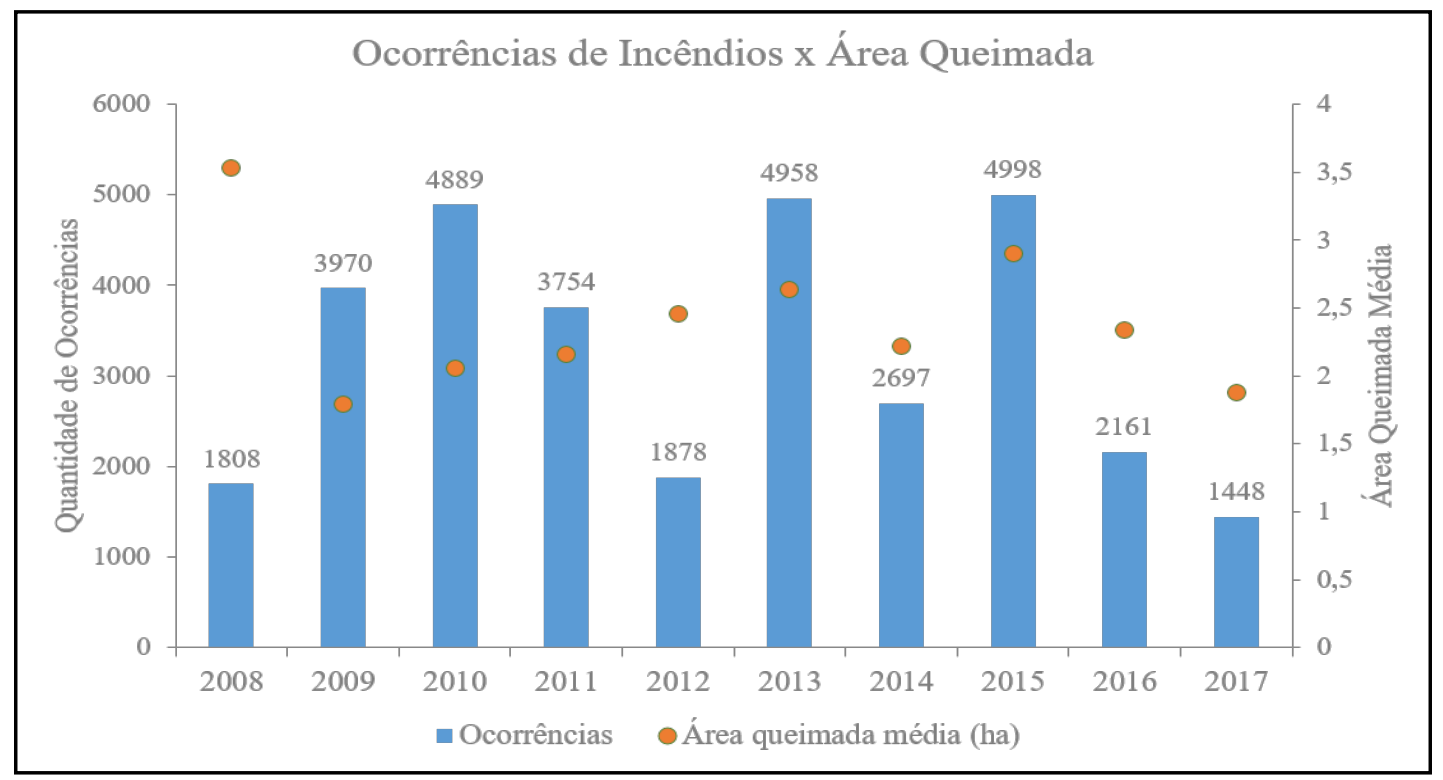

Fonte: Autores (2020)

A quantidade média de 8,92 ocorrências diárias de incêndios encontrada nesta pesquisa é bem superior aos 0,14 ocorrências diárias encontrados por Tetto et al. (2015) em sua análise histórica de incêndios florestais atendidos pela Klabin do Paraná entre nos anos de 1965 a 2009.

Entre os anos analisados pode-se perceber que houve picos de ocorrências sem distribuição uniforme, dificultando, dessa forma, o estabelecimento de estratégias de prevenção e combate de incêndios florestais.

Com uma correlação de Pearson de $-0,06$ entre a quantidade de ocorrências e a área atingida, fica evidente que independentemente da quantidade de ocorrências, as brigadas da região de estudo estão capacitadas para combater os incêndios, esse fator se deve em função do raio de atuação das equipes e a tecnologia embarcada nos seus sistemas de combate.

Apesar do número de ocorrências de incêndios, a média de área queimada foi de 2,39 ha, valor abaixo dos 8,4 ha analisados por Tetto et al. (2015), em plantios florestais no sul do Brasil e dos 613,61 ha do estudo de Torres et al. (2016), analisando a série histórica de unidades de conservação do Brasil de 2008 a 2012.

Corroborando com essa interdependência entre área média queimada e quantidade de ocorrências, Lima et al. (2018), em seu estudo de eficiência de combate aos incêndios florestais em unidades de conservação brasileiras, abordaram que a falta de correlação entre esses parâmetros se dá devido as diversas características do território nacional.

A maior dificuldade nessa disparidade entre os anos está diretamente ligada as causas dos incêndios florestais, pois por serem majoritariamente de ações criminosas, a previsão de quando e onde ocorrer é dependente apenas das ações dos incendiários.

Na Figura 4 e na Tabela 2 é possível observar o registro do número de ocorrências de incêndios e sua correlação ao longo dos meses com os elementos meteorológicos que interferem na ignição do fogo ao longo da série histórica de 10 anos. 
Figura 4 - Correlação mensal entre a influência dos elementos meteorológicos e a quantidade de ocorrências de incêndios durante o período de 2008 a 2017

Figure 4 - Monthly correlation between the influence of meteorological elements under the number of occurrences of fires during the period 2008 to 2017

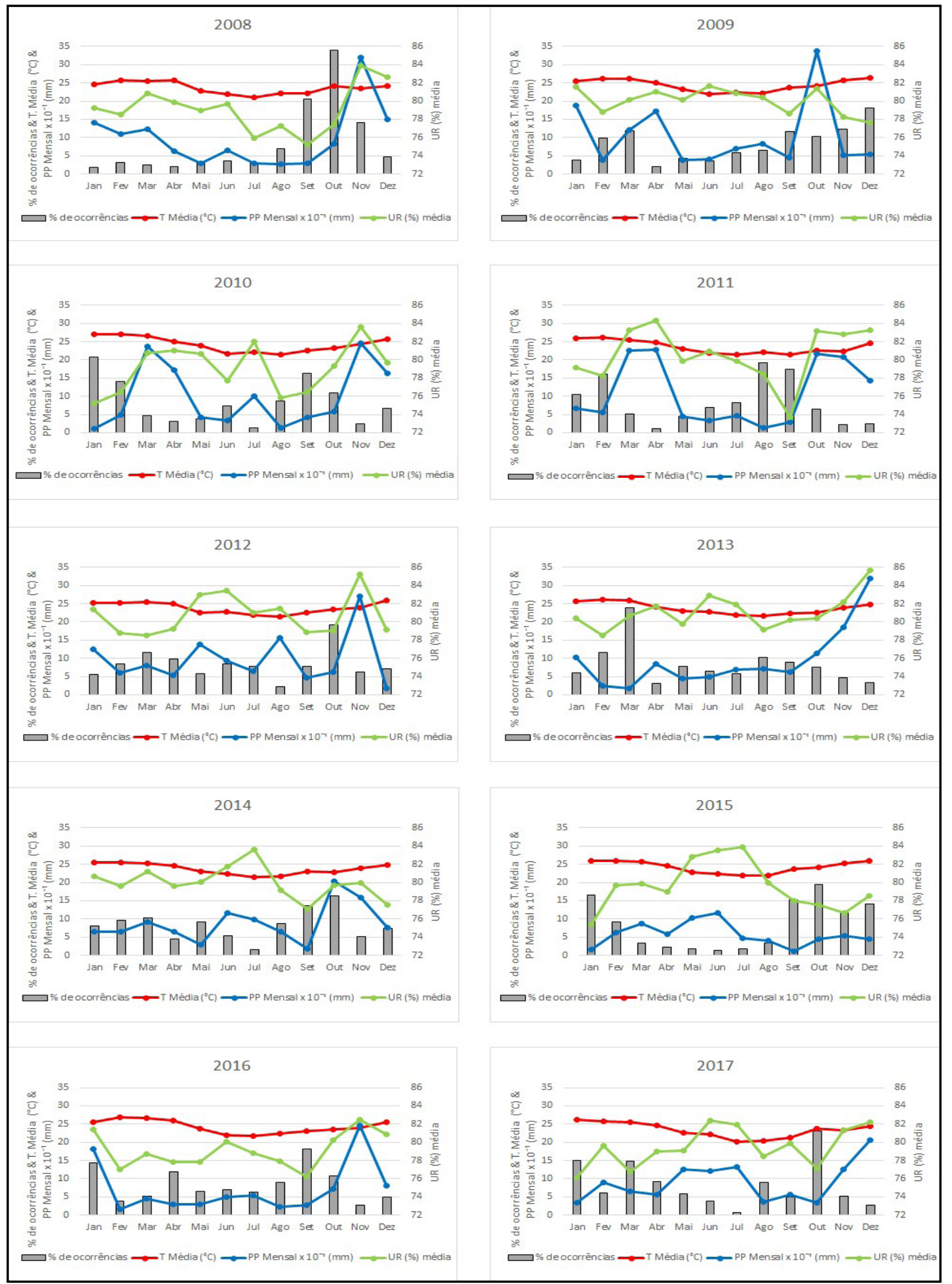

Fonte: Autores (2020) 
Tabela 2 - Resultados do coeficiente de correlação de Pearson entre os elementos meteorológicos analisados com o percentual de ocorrências de cada ano analisado na série histórica de 2008 a 2017

Table 2 - Pearson's correlation coefficient between the meteorological elements analyzed with the percentage of occurrences of each year analyzed in the historical series from 2008 to 2017

\begin{tabular}{ccccccccccc}
\hline Coeficiente de correlação de Pearson & 2008 & 2009 & 2010 & 2011 & 2012 & 2013 & 2014 & 2015 & 2016 & 2017 \\
\hline T média $\left({ }^{\circ} \mathrm{C}\right) \times$ \% de ocorrências & $-0,13$ & 0,55 & 0,27 & $-0,14$ & 0,24 & 0,34 & 0,09 & 0,53 & $-0,15$ & 0,45 \\
UR (\%) média x \% de ocorrências & $-0,26$ & $-0,80$ & $-0,86$ & $-0,85$ & $-0,47$ & $-0,45$ & $-0,61$ & $-0,61$ & $-0,61$ & $-0,61$ \\
PP mensal (mm) x \% de ocorrências & 0,05 & $-0,13$ & $-0,61$ & $-0,70$ & $-0,41$ & $-0,54$ & 0,08 & $-0,68$ & $-0,13$ & $-0,71$ \\
\hline
\end{tabular}

Fonte: Autores (2020)

Em que: T: temperatura; UR: umidade relativa; PP: precipitação.

Em média, a correlação de Pearson aplicada entre os meses do ano e os elementos meteorológicos apresentou correlação negativa moderada de $-0,61$ para a umidade relativa, baixa correlação negativa $(-0,38)$ para a precipitação média mensal e correlação desprezível $(0,21)$ para temperatura média. Observou-se que em florestas de produção, onde as causas atingem valores acima de $90 \%$ de origem antrópica intencional, a UR foi o elemento meteorológico que mais influenciou na possibilidade de ocorrer incêndios.

A correlação entre os elementos meteorológicos analisados e a quantidade de ocorrências é explicada pelo fator causa, representando $91,40 \%$ das ocorrências por incêndios criminosos. Divergindo do encontrado neste estudo, Seger et al. (2012) identificaram correlação entre a quantidade de incêndios e a precipitação média mensal, onde, quanto maiores os volumes de precipitação, menores foram as quantidades de incêndios na região do estudo.

Os meses de outubro e setembro, respectivamente, apresentaram os maiores índices de ocorrências média ao longo dos anos analisados, com 13,83 e 13,72\% das ocorrências, totalizando $27,54 \%$, entretanto estatisticamente diferiram apenas de abril, demonstrando o quão bem distribuídos são as ocorrências da área do estudo ao longo dos meses dos anos analisados (Tabela 3).

\section{Tabela 3 - Média de ocorrências ao longo dos meses do ano analisada na série histórica de} 2008 a 2017

Table 3 - Average occurrences over the months of the year analyzed in the historical series from 2008 to 2017

\begin{tabular}{cccc}
\hline Meses & Média de ocorrências & \% \\
\hline Out & 450,00 & $\mathrm{a}$ & 13,83 \\
Set & 446,30 & $\mathrm{a}$ & 13,72 \\
Jan & 356,80 & $\mathrm{ab}$ & 10,96 \\
Fev & 336,90 & $\mathrm{ab}$ & 10,35 \\
Mar & 310,40 & $\mathrm{ab}$ & 9,54 \\
Ago & 281,80 & $\mathrm{ab}$ & 8,66 \\
\hline
\end{tabular}

\begin{tabular}{cccc}
\hline Meses & \multicolumn{2}{l}{ Média de ocorrências } & \% \\
\hline Dez & 257,30 & $\mathrm{ab}$ & 7,91 \\
Nov & 213,80 & $\mathrm{ab}$ & 6,57 \\
Jun & 171,30 & $\mathrm{ab}$ & 5,26 \\
Mai & 165,00 & $\mathrm{ab}$ & 5,07 \\
Jul & 136,90 & $\mathrm{ab}$ & 4,21 \\
Abr & 127,50 & $\mathrm{~b}$ & 3,92 \\
\hline
\end{tabular}

Fonte: Autores (2020)

Em que: *Médias seguidas por uma mesma letra, em cada coluna, não diferem estatisticamente (Tukey, $\mathrm{p}>0,05)$. 


\section{Conclusão}

Incêndios florestais ocasionados por incendiários majoritariamente independem das condições meteorológicas, dessa maneira, a estratégia de combate aos incêndios deve contemplar distribuição de recursos ao longo dos meses do ano, a fim de minimizar os impactos ocasionados pelo fogo.

\section{Referências}

ALVARES, C. A. et al. Köppen's climate classification map for Brazil. Meteorologische Zeitschrift, Stuttgart, v. 22, n. 6, p. 711-728, 2013.

BARLOW, J. et al. The critical importance of considering fire in REDD+ programs. Biological Conservation, [s. l.], v. 154, n. 2012, p. 1-8, 2012.

GANTEAUME, A.; JAPPIOT, M. What causes large fires in Southern France. Forest Ecology and Managemen, [s. l.], v. 294, p. 76-85, 2013.

INDÚSTRIA BRASILEIRA DE ÁRVORES. Relatório Ibá 2017: ano base 2016. São Paulo, SP, 2017. 80 p.

INSTITUTO CAPIXABA DE PESQUISA, ASSISTÊNCIA TÉCNICA E EXTENSÃO RURAL. Programa de assistência técnica e extensão rural PROATER 2011 - 2013. Aracruz, 2011a. 15 p.

INSTITUTO CAPIXABA DE PESQUISA, ASSISTÊNCIA TÉCNICA E EXTENSÃO RURAL. Programa de assistência técnica e extensão rural PROATER 2011 - 2013. São Mateus, 2011 b. 26 p.

IRLAND, L. C. Extreme value analysis of forest fires from New York to Nova Scotia, 1950-2010. Forest Ecology and Management. [s. l.], v. 294, p. 150-157, 2013.

HEIKKILA, T. V.; GRONQVIST, R.; JURVELIUS, M. Wildland fire management: handbook for trainers. Roma: FAO, 2010. 248 p.

HINKLE, D. E.; WIERSMA, W.; JURS, S. G. Applied statistics for the behavioral sciences. Boston: [s. n.], 2003. v. 5. 756 p.

KÖPPEN, W. Das geographische System der Klimate. In: KÖPPEN, W.; GEIGER, R. (ed.). Handbuch der Klimatologie. Berlin: Gebrüder Borntraeger, 1936. p. 1-44.

LIMA, G. S. et al. Avaliação da eficiência de combate aos incêndios florestais em unidades de conservação brasileiras. Floresta. Curitiba, v. 48, n. 1, p. 113-122, jan./mar. 2018.

NUNES, A. et al. Vulnerabilidade a incêndios na Europa Mediterrânea. Abordagem conceptual e a utilização de dados de satélite. In: JORNADAS LUSÓFONAS DE CIÊNCIAS E TECNOLOGIAS DE INFORMAÇÃO GEOGRÁFICA, 1., Coimbra. Atas [...]. Coimbra: [s. n.], 2015.

OLAWOYIN, R. Nanotechnology: The future of fire safety. Safety Science, [s. l.], v. 110, p. 214$221,2018$.

RODRÍGUEZ, M. P. R. et al. Comparação entre o perfil dos incêndios florestais de Monte Alegre, Brasil, e de Pinar del Rio, Cuba. Floresta, Curitiba, v. 43, n. 2, p. 231-240, abr./jun. 2013.

SEGER, C. D. et al. Análise dos incêndios florestais em vegetação nativa de vinte e dois municípios da região leste do estado do Paraná - Brasil. Caminhos de Geografia, Uberlândia, v. 13, n. 43, p. 30-40, out. 2012.

SIBANDA, C. Modelling forest fire behaviour and carbon emission in the Ludikhola 
Watershed, Gorkha District, Nepal.2011. Dissertação (Mestrado em Ciências de Geo-informação e Observação da Terra) - University of Twente, Enschede. Netherlands, 2011.

SOARES, R. V. Perfil dos incêndios florestais no brasil de 1984 a 1987. Floresta, Curitiba, v. 18, n. 1/2, p. 94-121, 1988.

SOARES, R. V.; BATISTA, A.C. Incêndios florestais: controle, efeitos e uso do fogo. Curitiba: [s. n.], 2007. $264 \mathrm{p}$.

TETTO, A. F. et al. Incêndios florestais atendidos pela Klabin do Paraná no período de 1965 a 2009. Cerne, Curitiba, v. 21 n. 3, p. 345-351, 2015.

TORRES, F. T. P. et al. Perfil dos incêndios florestais em unidades de conservação brasileiras no período de 2008 a 2012. Floresta, Curitiba, v. 46, n. 4, p. 531-542, out./dez. 2016.

TORRES, F. T. P. Relações entre fatores climáticos e ocorrências de incêndios florestais na cidade de Juiz de Fora (MG). Caminhos de Geografia, [s. l.], v. 7, n. 18, p.162-171, jun. 2006. 